PUBLIPRENEUR POLIMEDIA: JURNAL ILMIAH JURUSAN PENERBITAN

POLITEKNIK NEGERI MEDIA KREATIF

Vol.9, No. 1, Juni 2021 hal. 47-52

Submitted: 10 April 2021

Revised: 7 Mei 2021

Accepted: 15 Juni 2021

\title{
Preliminary Study of the Effect of Technology Integration on the Growth of the Printing Industry in Indonesia
}

\author{
Haryasena Gusti Andayu ${ }^{1^{*}}$ dan Handika Dany Rahmayanti ${ }^{2}$ \\ 1Program Studi Magister Manajemen, Universitas Esa Unggul, Indonesia \\ 2Program Studi Teknik Kemasan, Politeknik Negeri Media Kreatif \\ E-mail: gusti.haryasena@gmail.com ${ }^{1}$
}

\begin{abstract}
Digital globalization in the economic sector is no exception in the printing industry. For hundreds of years the print media dominated for the dissemination of information. However, currently the dominance of the print media industry is now in danger of being shifted along with technological developments. This study shows how the growth of the print industry in Indonesia for several years. Based on the results of the study, the number of printing industries from 2011-2015 experienced a decline in almost all regions of Indonesia, including the provinces of West Java, East Java, DKI Jakarta, Banten, Kalimantan, Central Java and Sumatra. The decline in numbers occurred in the printing industry of newspapers, magazines, books and advertising. Especially for the packaging industry, it did not experience a significant decline and was relatively stable.
\end{abstract}

Keyword: printing industry, digital technology, business strategy

\section{Kajian Sederhana Pengaruh Integrasi Teknologi Terhadap Pertumbuhan Industri Percetakan di Indonesia}

\begin{abstract}
ABSTRAK
Globalisasi digital pada sektor perekonomian tak terkecuali pada industri percetakan. Selama ratusan tahun media cetak mendominasi bagi penyebaran informasi. Namun saat ini dominasi industri media cetak kini terancam tergeser seiring perkembangan teknologi. Pada penelitian ini ditampilkan bagaimana pertumbuhan industri cetak di Indonesia selama beberapa tahun. Berdasarkan hasil kajian jumlah industri percetakan dari tahun 2011-2015 mengalami penurunan jumlah hampir di semua daerah Indonesia yakni meliputi provinsi Jawa Barat, Jawa Timur, DKI Jakarta, Banten, Kalimantan, Jawa Tengah dan Sumatera. Penurunan jumlah terjadi pada, industri cetak koran, majalah, buku dan advertising. Khusus untuk industri packaging tidak mengalami penurunan signifikan dan relatif stabil.
\end{abstract}

Kata kunci: industri cetak, teknologi digital, strategi bisnis

\section{PENDAHULUAN}

Media cetak mendominasi bagi penyebaran informasi selama ratusan tahun. Mesin cetak juga telah merevolusi perkembangan ilmu pengetahuan. Namun saat ini dominasi industri cetak terancam 
tergeser seiring perkembangan teknologi. Kehadiran internet telah mengubah total peta industri media. Lebih cepat dalam penyampaian informasi, praktis, mudah diakses serta lebih murah merupakan beberapa keunggulan yang ditawarkan dari pemberitaan internet daripada di media cetak. Apalagi kemajuan teknologi gawai yang memungkinkan orang mengakses internet dengan mudah dan praktis. Penetrasi internet yang semakin besar telah mengubah perilaku masyarakat dalam mengkonsumsi media secara langsung (Sholahuddin, 2013).

Ditambah lagi maraknya media seperti facebook, Instagram dan Twitter yang dalam tempo singkat membuat orang begitu mudah bertukar informasi. Faktor kecepatan dan kepraktisan inilah sehingga mendorong orang mulai beralih ke media online guna memuaskan kebutuhan informasi. Jika kondisi ini terus berjalan maka masa depan media cetak akan terancam. Dalam mempertahankan bisnisnya, para pelaku industri cetak tengah menghadapi tantangan berat. Bukan hanya menghadapi persaingan sesama industri cetak, namun kehadiran digitalisasi multimedia dengan berbagai keunggulannyalah yang merupakan tantangan terberat.

Sebagai contoh di industri media massa menunjukkan fakta bahwa banyak media cetak kehilangan pembaca secara signifikan. Oplah serta pendapatan iklan pun juga terus turun. Sejumlah media cetak di berbagai dunia dilaporkan mulai berjatuhan karena penjualan koran/majalah/tabloid serta pendapatan iklan merupakan nyawa mereka (Lenggawa, 2019).

Pada penelitian ini akan ditampilkan bagaimana pertumbuhan industri cetak di Indonesia selama beberapa tahun. Mengenai nasib industri media cetak di Indonesia, sejumlah pengamat mengutarakan pendapat yang berbeda. Sebagian mengatakan masa depan pers cetak Indonesia masih prospektif sedangkan yang lain memprediksi bisnis cetak akan surut (Kusuma, 2016). Industri media cetak tidak bisa hanya diam di tengah gempuran media internet yang amat kuat ini. Oleh karena itu, diperlukan perubahan strategi bisnis agar perusahaan tetap diterima konsumen dan menguntungkan secara bisnis.

Tidak hanya media cetak hanya, industri di bidang percetakan seperti buku, kemasan (packaging) serta iklan (advertising) juga terkena dampak dari pengaruh integrasi teknologi digital. Globalisasi digital pada sektor perekonomian saat ini juga membawa banyak dampak pada liberalisasi perdagangan secara global. Kemajuan teknologi informasi memperluas ruang lingkup perdagangan tanpa adanya batasan-batasan yang dapat menghambat ekspansi kemajuan perusahaan.

Perusahaan yang teknologinya maju memiliki peluang besar memenangkan persaingan. Terlebih, perkembangan ilmu pengetahuan dan teknologi semakin pesat menghantarkan ke arah revolusi digital atau revolusi 4.0. Informasi mengenai bagaimana pertumbuhan industri cetak di tengah gempuran integrasi teknologi digital serta bagaimana strategi agar industri cetak bisa bertahan di tengah persaingan sangat diperlukan dan akan dipaparkan pada artikel ini..

\section{METODE PENELITIAN}

Penelitian ini menggunakan metode penelitian kuantitatif dan deskriptif kualitatif. Adapun teknik pengumpulan data melalui data yang diperoleh dari Buku Direktori Persatuan Perusahaan Grafika Indonesia (PPGI) Tahun 2011/2012, 2013/2014 dan 2014/2015. Data yang diambil meliputi jumlah perusahaan cetak kemasan (packaging), buku, majalah, koran, iklan (advertising) di beberapa kota di provinsi Jawa Barat, Jawa Timur, DKI Jakarta Banten, Kalimantan, Jawa Tengah 
dan Sumatera. Selain perusahaan cetak yang disebutkan diatas masuk kategori lainnya.

Selain itu digunakan juga pendekatan studi literatur dengan menelusuri berbagai sumber bacaan seperti jurnal-jurnal ilmiah, tesis dan buku. Data yang didapatkan menjadi metode analisis penulis dalam mengkaji Pengaruh Integrasi Teknologi Terhadap Pertumbuhan Industri Percetakan di Indonesia.

\section{HASIL DAN PEMBAHASAN}

Tak dapat dipungkiri bahwa globalisasi digital saat ini juga membawa banyak dampak pada pertumbuhan industri percetakan di Indonesia. Pada penelitian ini dipaparkan mengenai jumlah pertumbuhan industri percetakan di Indonesia. Data yang dipaparkan terbatas pada 3 kategori yakni 1) Industri kemasan (packaging); 2) Buku, Majalah, dll; 3) Iklan (advertising). Di luar 3 kategori tersebut masuk kategori lainnya.

Gambar 1 menunjukkan data industri percetakan di beberapa daerah di Indonesia. Data diambil dari beberapa kota di Indonesia yang tersebar di Provinsi Jawa Barat, Jawa Timur, DKI Jakarta, Banten, Kalimantan, Jawa Tengah dan Sumatera. Lebih sempit lagi yakni meliputi kota Bekasi, Bogor, Cirebon, Depok, Garut, Indramayu, Subang, Sukabumi, Sumedang dan Tasikmalaya untuk Provinsi Jawa Barat. Untuk provinsi Jawa Timur diambil data dari kota Surabaya, Jember, Banyuwangi, Pasuruan, Malang, Sidoarjo, Sumenep, Madiun dan Ngawi.

Di provinsi Banten sendiri diwakili oleh kota Pandeglang, Rangkasbitung, Serang dan Tangerang. Kota Batang, Demak, Jepara, Klaten, Kudus, Malang, Purwokerto, Purworejo, Semarang, Solo dan Tegal mewakili Jawa Tengah. Sedangkan untuk Provinsi DKI Jakarta diambil data seluruh kotamadya kecuali kepulauan seribu. Daerah luar pulau Jawa diambil data dari pulau Sumatera dan
Kalimantan. Pulau Sumatera diambil data dari provinsi Sumatera Utara, Sumatera Barat, Jambi dan Sumatera Selatan sedangkan Pulau Kalimantan diambil data dari kota Banjarmasin, Samarinda, Balikpapan, Tenggarong, Tarakan dan Palangkaraya.

Dari gambar 1 menunjukkan bahwa jumlah industri percetakan mengalami penurunan jumlah hampir di semua daerah. Tren menurunnya media cetak dan diganti ledakan media digital juga telah dilaporkan oleh beberapa peneliti (Galarneau dan Joseph, 2009). Bergesernya kebiasaan pasar mengonsumsi media baru dengan koneksi internet sehingga mengakibatkan media cetak mulai ditinggalkan tentunya menjadi ancaman bagi keberlangsungan industri cetak. Faktor inilah yang mempengaruhi pertumbuhan industri cetak di Indonesia.

Kehadiran internet menuntut industri cetak menerapkan konsep konvergensi media seperti e-paper, radio streaming, media online, e-books serta media sosial. Tidak hanya media cetak seperti koran dan majalah, industri cetak lain seperti buku dan advertising juga mengalami penurunan. Gambar 2 dan Gambar 3 menunjukkan data jumlah industri cetak di bidang packaging, buku, majalah, advertising dan lainnya dari tahun 2011-2015 di daerah Jawa Barat dan Kalimantan.

Harga kertas yang semakin mahal juga menjadi faktor industri cetak menjadi semakin sulit untuk bertahan. Belum lagi ketersediaan bahan baku yang sulit didapat. Kampanye pelestarian lingkungan dengan tidak menebang pohon dan mengurangi penggunaan kertas cetak juga menjadi ancaman tersendiri. Pilihan bagi industri cetak mau tak mau harus mentransformasi diri untuk ikut menguasai perkembangan teknologi digital yang sudah, sedang dan akan terjadi lebih jauh (Andoko, 2010). 


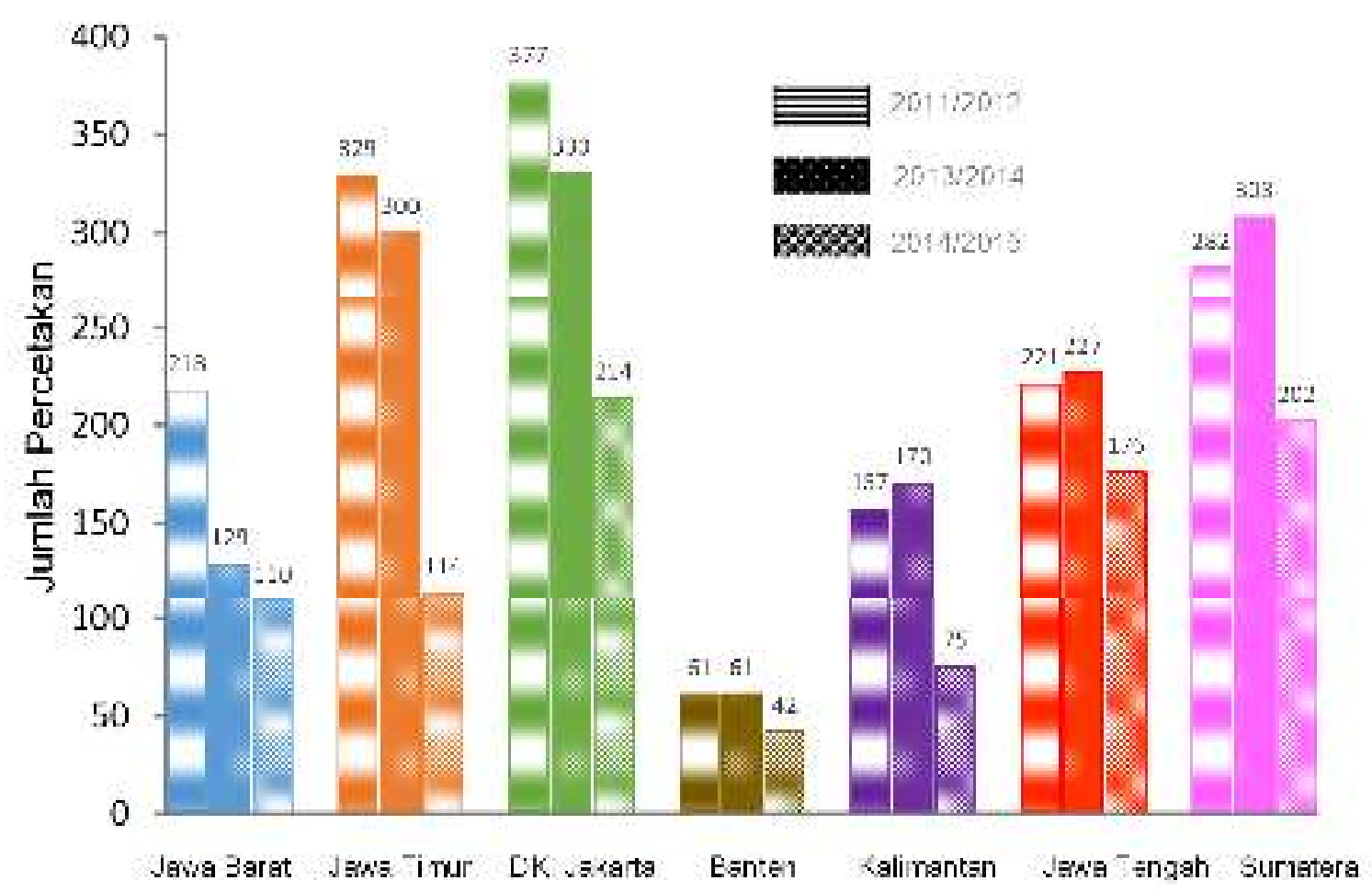

Gambar 1 Data pertumbuhan industri percetakan di beberapa daerah di Indonesia

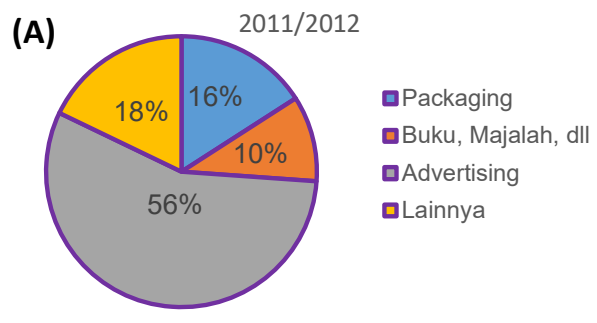

(B)

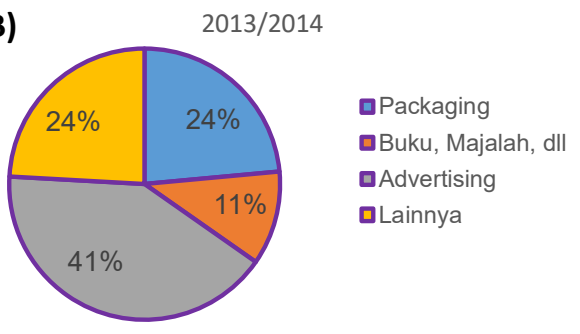

(C)

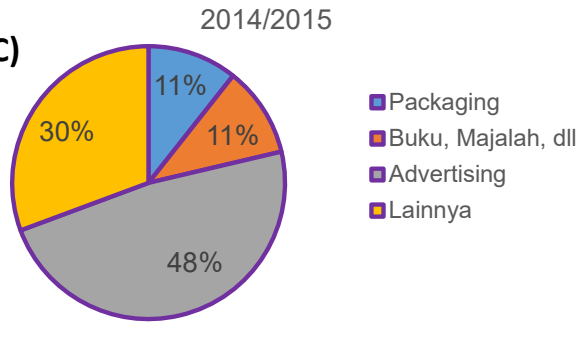

Gambar 2 Data pertumbuhan industri percetakan di Jawa Barat
Untuk media cetak seperti koran, majalah dan tabloid, strategi lain perlu dilakukan contohnya dengan mengintegrasikan konten media ke dalam tablet elektronis. Pola strategi bersaing dalam industri cetak seperti ini merupakan salah satu wujud inovasi dan adaptasi dengan kemajuan teknologi (Sugiya, 2012).

Industri mungkin juga perlu berimajinasi mengenai apa yang akan terjadi di masa depan guna melakukan perubahan. Imajinasi dapat menghasilkan penemuan hebat. Dengan kekuatan imajinasi, tidak ada fenomena yang akan dianggap sepele. Contohnya imajinasi juga diyakini telah berkontribusi pada penemuan discovery teori gravitasi universal oleh Newton, dari sekadar mempertimbangkan jatuhnya apel (Rahmayanti, 2016). Barangkali dengan berimajinasi tentang masa depan industri cetak dapat menghasilkan terobosan baru yang dapat mempertahankan bisnisnya. 
Khusus untuk industri packaging relatif stabil karena seperti yang kita ketahui kemasan merupakan bagian yang paling penting untuk sebuah produk. Kemasan umumnya digunakan untuk mengemas berbagai jenis produk seperti minyak, minuman, produk kecantikan, serta obat-obatan (Mahardika dkk, 2020). kemasan produk berfungsi juga untuk membangun citra dan brand. Walaupun pertumbuhan industri kemasan melambat, beberapa investor asing agaknya masih berminat masuk ke industri dalam negeri. Jumlah penduduk Indonesia yang besar dan masyarakat ekonomi menengah yang terus tumbuh mendorong pertumbuhan consumer goods sehingga perlu didukung oleh industri kemasan. Hal ini menjadi potensi yang menarik bagi para investor.

(A) $2011 / 2012$

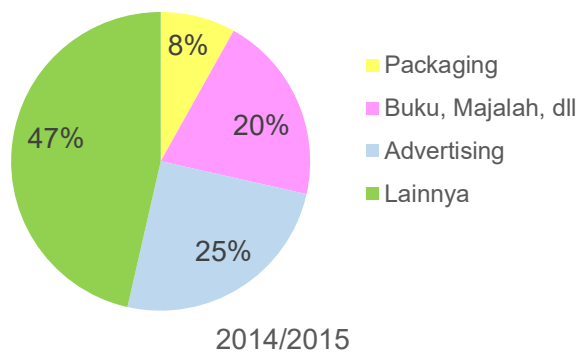

(B)

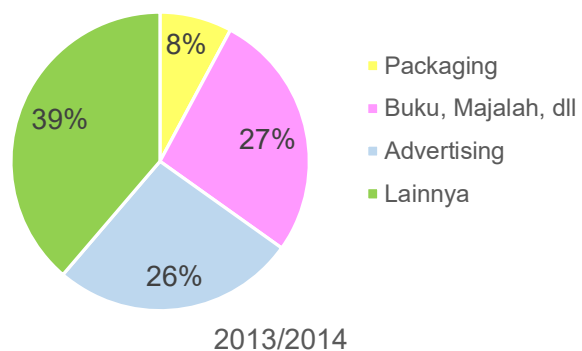

(C)

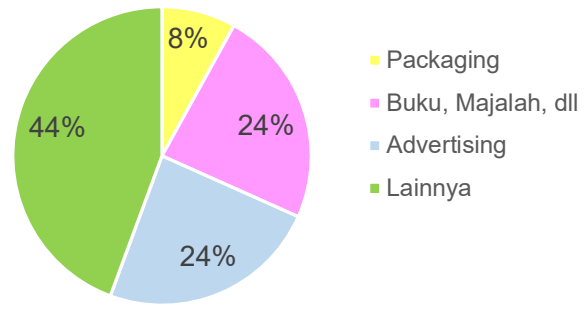

Gambar 3 Data pertumbuhan industri percetakan di Kalimantan

\section{KESIMPULAN}

Berdasarkan hasil kajian jumlah industri percetakan dari tahun 2011-2015 mengalami penurunan jumlah hampir di semua daerah Indonesia yakni meliputi provinsi Jawa Barat, Jawa Timur, DKI Jakarta, Banten, Kalimantan, Jawa Tengah dan Sumatera. Penurunan jumlah terjadi pada, industri cetak koran, majalah, buku dan advertising. Khusus untuk industri packaging relatif stabil karena seperti yang kita ketahui kemasan merupakan bagian yang paling penting untuk membangun citra dan brand. Jumlah penduduk Indonesia yang besar dan masyarakat ekonomi menengah yang terus tumbuh mendorong pertumbuhan consumer goods sehingga perlu didukung oleh industri kemasan. Hal ini menjadi potensi yang menarik bagi para investor.

\section{DAFTAR PUSTAKA}

Andoko, Andrey. (2010), “Teknologi Digital: Akankah Media Cetak Berakhir?" Jurnal Ultimatics. 2 (1).

Galarneau, Joseph. (2009), Publishing Research Quarterly, 25(2):89-93.

Lenggawa, V. A. (2019). Strategi Jawa Pos Dalam Menghadapi Persaingan Bisnis Media Di Era Revolusi Industri 4.0. Konvergensi: jurnal ilmiah ilmu komunikasi, 1(1), 19-38.

Kusuma, S. (2016). Posisi media cetak di tengah perkembangan media online di Indonesia. Jurnal InterAct, 5(1), 5671.

Mahardika, M., Rahmayanti, H., \& Majid, A. (2020). STUDY OF DEFECT ON LLDPE PLUG FOR TELON OIL PRODUCTS USING A HAITIAN MOLDING INJECTION MACHINE 1600MA AT PT X. Jurnal Ilmiah Publipreneur, 8(2), 65-74.

Rahmayanti, H. D., Utami, F. D., \& Abdullah, M. (2016). Physics model for wringing of wet cloth. European Journal of Physics, 37(6), 065806.

Sholahuddin, S. (2014). STRATEGI 
PENGEMBANGAN PRODUK DI INDUSTRI MEDIA CETAK DI INDONESIA (Bertahan di tengan Persaingan Media Online. Benefit: Jurnal Manajemen dan Bisnis, 17(1), 917.

Sugiya A. (2012), Strategi Tansformasi Konvergensi Media Studi Kasus Grand Strategy Harian Kompas. [tesis], Universitas Indonesia. 